\title{
La gentrificación rural como factor de persistencia de la población originaria y de las actividades agrícolas: indicios desde Morelos, México
}

\author{
Matthew James Lorenzen Martiny, Universidad de Paris 1 Panthéon-Sorbonne, Francia
}

\begin{abstract}
Resumen: Este artículo se basa en una investigación efectuada en tres municipios del estado de Morelos, México, donde se llevaron a cabo entrevistas semiestructuradas a productores agrícolas y a habitantes rurales. Se aborda la hipótesis de que procesos de gentrificación rural puedan fomentar la persistencia de la población originaria y de las actividades agrícolas por medio de la creación de empleos complementarios. Esta hipótesis impugnaría una parte de la literatura sobre la gentrificación, que sostiene una noción rígida, aplicable esencialmente a situaciones de renovación urbana, y que implica el desplazamiento de la población originaria por la llegada de una nueva población de ingresos elevados. Por el contrario, este trabajo se suma a otra corriente de investigadores que defienden un concepto de gentrificación más flexible, aplicable a otros ámbitos geográficos (espacios periurbanos y rurales) y a situaciones de nuevas construcciones inmobiliarias, donde el fenómeno del desplazamiento no es generalizado. La investigación de campo hizo patente que lejos de contribuir a un desplazamiento, la afluencia de grupos de ingresos elevados, ya sean turistas o residentes temporales o permanentes, ha promovido la creación de empleos locales que benefician a la población local.
\end{abstract}

Palabras clave: gentrificación rural, nueva ruralidad, rurbanización

\begin{abstract}
This paper is based on research carried out in three municipalities of the state of Morelos, Mexico, where we conducted semi-structured interviews with farmers and rural inhabitants. We address the hypothesis that processes of rural gentrification can incite the persistence of the native population and of agricultural activities through the creation of supplementary sources of work. This hypothesis challenges a part of the literature on gentrification that maintains a rigid notion of gentrification, essentially applicable to situations of urban renovation, and that involves the displacement of the native population with a newly arrived high-income population. In contrast, this paper joins the arguments of another group of researchers that defend a more flexible notion of gentrification, applicable to other geographical areas (peri-urban and rural spaces) and to contexts involving new real-estate developments, where the displacement phenomenon is far from being widespread. Our fieldwork made clear that far from contributing to the displacement of the native population, the influx of high-income groups, be they tourists, temporal or permanent residents, has promoted the creation of local employment opportunities that benefit the local population.
\end{abstract}

Keywords: Rural Gentrification, New Rurality, Rurbanisation

\section{Introducción}

$\Lambda$ bordamos en este artículo la hipótesis, basada en una investigación efectuada en el estado de Morelos, México, de que los procesos de gentrificación rural puedan fomentar en ciertos contextos la persistencia de la población originaria y de las actividades agrícolas mediante la creación de empleos complementarios. Esta hipótesis impugnaría una parte de la literatura de la gentrificación que sostiene que un elemento fundamental de este fenómeno es el desplazamiento de la población originaria causada por la llegada de una nueva población de ingresos elevados. Por el contrario, este trabajo se suma a otra corriente de investigadores que argumentan no solamente que el desplazamiento no es un elemento generalizado de la gentrificación sino que ésta puede ser un factor de persistencia de los habitantes originarios.

Resumimos en la primera parte del artículo estas dos posiciones contrastantes presentes en la literatura de la gentrificación, demostrando, en la segunda parte, que la gentrificación rural en el estado de Morelos, México, lejos de contribuir a un desplazamiento de los pobladores originarios, ha

Revista Internacional de Ciencias Sociales

Volumen 3, Número 1, <http://lascienciassociales.com>, ISSN 2530-4909

(C) Global Knowledge Academics. Matthew James Lorenzen Martiny.

Todos los derechos reservados. Permisos: soporte@gkacademics.com

Republicado de Revista Internacional de Ciencias Sociales Internacionales 3(1), 2014 (pp. 1-14) 
estimulado la creación de empleos locales que complementan a las actividades agrícolas, promoviendo un anclaje de la población.

\section{La gentrificación, el desplazamiento y el anclaje}

La noción de gentrificación -un neologismo basado en la palabra gentry, que se refiere a un sector de la aristocracia inglesa- fue concebida inicialmente por la socióloga británica Ruth Glass en 1964, en un texto ampliamente aludido donde describe la invasión de ciertos barrios londinenses por personas de clases media y alta, así como el desplazamiento de los habitantes originarios de clase obrera después de la terminación de sus contratos de arrendamiento, cuyas antiguas viviendas eran renovadas, convirtiéndose así en residencias caras y lujosas (Glass, 1964). Sin embargo, el concepto de gentrificación no fue desarrollado más detalladamente sino hasta 15 años después, a partir del final de los años 1970. Diversos autores -esencialmente británicos, estadounidenses y canadienses, aunque recientemente también de otras nacionalidades-se vieron rápidamente implicados en intensas discusiones teóricas, que continúan actualmente, sobre las causas y los efectos de la gentrificación.

En cuanto a los efectos, el elemento que ha causado más discusión es sin duda el del desplazamiento de los habitantes originarios, que sería provocado por las alzas en los alquileres y la recuperación de las viviendas por parte de los propietarios para renovarlas y vender o alquilarlas a precios elevados a los nuevos residentes "gentrificadores". Por un lado, algunos autores han criticado los intentos de generalizar el efecto de desplazamiento, indicando que se trata de un impacto coyuntural y que, al contrario, la gentrificación puede ser un factor de persistencia de los habitantes originarios. Por el otro, ciertos autores han insistido que el desplazamiento, directo o indirecto, es un efecto ineludible y central de la gentrificación. Resumimos en esta parte estas dos posiciones contrastantes.

\section{La gentrificación como factor de anclaje de la población originaria}

Tanto en la literatura de la gentrificación urbana como de la gentrificación rural, se ha criticado la generalización del efecto de desplazamiento, que se ha vuelto parte integrante de muchas definiciones de la gentrificación. ${ }^{1}$

Desde la literatura de la gentrificación urbana, autores como Lance Freeman $(2005,2008)$, Peter Byrne (2003) y Jacob Vigdor (2001, 2002) han indicado, basándose en investigaciones en Nueva York y Boston, que el cambio de la población en barrios en procesos de gentrificación no es mayor al cambio de la población en barrios no gentrificados, desacreditando la idea de un desplazamiento a gran escala provocado por la gentrificación. Esto sugeriría una coexistencia, por lo menos durante un primer periodo, entre los gentrificadores y los habitantes originarios, cuya presencia podría ya sea erosionarse gradualmente o mantenerse, creando así barrios socio-económicamente diversificados (Freeman, $2008: 4-5$ ).

Por otra parte, estos autores argumentan que la gentrificación puede en realidad crear los motivos y los medios para la permanencia de los habitantes originarios, compensando en muchos casos el efecto negativo del incremento en los alquileres. Esto sería posible por razón de la creación de empleos (sobre todo en los servicios) que conlleva la llegada de habitantes con mayor poder de compra, de la desconcentración espacial de la pobreza, de la revitalización general de las zonas urbanas, y del mejoramiento de los servicios públicos y privados -en el primer caso, asociado al incremento de los ingresos de los gobiernos locales al haber una mayor recaudación fiscal con la presencia de nuevos habitantes de clases media y alta.

En la literatura de la gentrificación rural, las críticas de la generalización del efecto de desplazamiento han venido sobre todo de Laurie Guimond y Myriam Simard, quienes han estudiado la gentrificación en pequeñas localidades de Quebec. Guimond y Simard (2010: 460) reconocen que la

\footnotetext{
${ }^{1}$ Por ejemplo, para Lees, Slater y Wyly (2010: xvi), la gentrificación supone la reinversión de capital en una zona, la revalorización social de ese espacio por razón de la llegada de nuevos habitantes de ingresos altos, cambios en el entorno físico, y el desplazamiento directo o indirecto de los grupos menos acomodados.
} 
llegada de nuevos habitantes de ingresos altos puede contribuir al incremento de los alquileres y de los precios de los bienes inmuebles, pero afirman que esto no implica sistemáticamente un desplazamiento, especialmente en contextos rurales donde, a diferencia de los contextos urbanos, los habitantes originarios suelen ser propietarios de sus tierras y viviendas, pudiendo entonces beneficiarse de un incremento en los precios de los bienes inmuebles.

Por otra parte, Guimond y Simard (2010: 460) argumentan que un análisis de los impactos de la gentrificación no se debe enfocar únicamente en el efecto negativo del desplazamiento sino que debe intentar comprender la diversidad de impactos, tanto negativos como positivos, de la llegada de nuevos habitantes de ingresos elevados a una localidad, y esto no para desestimar o esconder los efectos negativos sino para comprender el fenómeno de la gentrificación en su totalidad. En este sentido, Simard (2011: 107) enumera toda una serie de posibles impactos positivos de la gentrificación rural, que incluyen la creación de empleos y empresas, la recuperación demográfica de los pueblos, la subsistencia de ciertos servicios de proximidad, el desarrollo de la economía residencial, las colaboraciones entre nuevos habitantes y habitantes originarios en diversos proyectos, la valorización de ciertos saberes y actividades artísticas y artesanales locales, la expansión de la oferta cultural, entre otros.

En cuanto al punto fundamental de la creación de empleos, Guimond y Simard (2008, 2010: 455) afirman que la llegada de nuevos habitantes de ingresos elevados y la construcción o renovación de casas y negocios representan fuentes importantes de trabajo en la construcción, los servicios y el comercio. La estabilización e incluso el aumento de la población en las localidades, resultado de la llegada de los nuevos habitantes, permitirían el mantenimiento de los servicios de proximidad y representarían un apoyo a las empresas y empleos locales (Guimond y Simard, 2010: 454). La reanimación cultural y la valorización de los saberes y actividades artísticas y artesanales locales podrían a su vez contribuir a la creación de empleos al fomentarse la atracción turística de ciertos pueblos (Simard, 2007: 206).

\section{El desplazamiento como efecto ineludible y central de la gentrificación}

Otro grupo de autores ha insistido en considerar el desplazamiento como un efecto inherente de la gentrificación. Sin embargo, para demostrar el carácter ineludible y central del desplazamiento, estos autores han tenido que ampliar el significado ordinario de ese concepto para incluir efectos de "desplazamiento indirecto", como veremos enseguida.

Así, por ejemplo, Mark Davidson y Loretta Lees (2010), estudiando la gentrificación creada por la construcción de nuevos inmuebles (a diferencia de la renovación de inmuebles antiguos), reconocen que el desplazamiento directo e inmediato de los habitantes originarios no ocurre cuando los nuevos inmuebles se construyen en terrenos baldíos o en antiguos espacios industriales. No obstante, los autores (Davidson y Lees, 2010: 398) afirman que incluso en esos casos existen formas de desplazamiento indirecto, a saber, la pérdida del sentimiento de pertenencia - un desplazamiento sociocultural- y el desplazamiento por exclusión. La primera sería provocada por los cambios físicos y sociales en un barrio en proceso de gentrificación y podría llevar a la mudanza de ciertos habitantes originarios que dejan de sentirse a gusto donde viven (Davidson y Lees, 2010: 406). Por su parte, el desplazamiento por exclusión implica, según los autores (Davidson y Lees, 2010: 405-406), la incapacidad de las personas de ingresos modestos (ya sean del barrio en proceso de gentrificación o de otro barrio) de acceder a las nuevas viviendas gentrificadas, lo que podría llevar a un desplazamiento de algunos jóvenes que se emancipan del hogar familiar y que no pueden costear la nueva vivienda disponible localmente.

Tom Slater (2009), por su parte, ha puesto en duda varias aseveraciones de los autores que niegan la centralidad del desplazamiento. En primer lugar, Slater (2009: 304) considera que la comparación entre el cambio de la población en barrios gentrificados y no gentrificados es inequitativa porque las mudanzas son más probables en barrios de clase trabajadora, donde la mayoría de las personas alquilan sus viviendas, a diferencia de los barrios de clases media y alta, donde las personas suelen ser propietarias -es decir que los arrendatarios tendrían más probabilidades de cambiar 
frecuentemente de residencia que los propietarios. En segundo lugar, el autor (Slater, 2009: 305) argumenta que el desplazamiento directo (provocado esencialmente por las alzas de los alquileres y la terminación de los contratos de arrendamiento) sucede ante todo en los momentos iniciales de la gentrificación pero que posteriormente las formas de desplazamiento indirecto (la pérdida del sentimiento de pertenencia y el desplazamiento por exclusión), que implican una movilidad menos significativa, se vuelven más importantes. Finalmente, Slater (2009: 306) afirma que la razón por la cual hay relativamente poco desplazamiento en algunos contextos no es porque los habitantes aprecian los aspectos positivos de la gentrificación -al contrario, serían seriamente afectados por las alzas de los alquileres y de los precios de los bienes y servicios- sino porque se encuentran acorralados por procesos de gentrificación a gran escala que no dejan muchas alternativas residenciales de bajo costo a una distancia permisible.

\section{La gentrificación como factor de anclaje de la población originaria: indicios desde tres municipios de Morelos, México}

Este breve recorrido por la literatura de la gentrificación muestra que el fenómeno del desplazamiento de la población originaria ha sido cuestionado por diferentes estudiosos de la gentrificación urbana y rural. No obstante, otros autores no han tardado en defender la importancia del desplazamiento, notando que hay efectos de desplazamiento indirecto - la pérdida del sentimiento de pertenencia y la exclusión-, además del desplazamiento directo causado por las alzas de los alquileres y la terminación de los contratos de arrendamiento.

En esta parte del artículo exponemos nuestra investigación empírica, basada en trabajo de campo efectuado en tres municipios del estado de Morelos, México. Veremos que los resultados de nuestra investigación corroboran los puntos de vista de los autores que critican la generalización del efecto de desplazamiento y que instan a estudiar los impactos tanto negativos como positivos de la gentrificación. Precisamente, estudiaremos en las páginas que siguen los efectos positivos y negativos de la gentrificación en los municipios de estudio.

\section{Hipótesis y regiones de estudio}

Como ya lo hemos indicado, nuestra hipótesis se suma a una corriente de autores que argumentan que la gentrificación no conduce necesariamente a un desplazamiento de la población originaria, pudiendo ser, inversamente, un factor de anclaje de esa población, especialmente a través de la creación de empleos ligada a la llegada de nuevos habitantes con un mayor poder de compra. En otras palabras, argumentamos que la llegada de nuevos habitantes de ingresos elevados ha impulsado la demanda de bienes y servicios, incitando a su vez la formación de empresas y de empleos para satisfacer esa demanda, motivando y haciendo posible la persistencia de la población originaria. Nuestro argumento va más lejos al afirmar que los nuevos empleos creados son en muchos casos complementarios a las actividades agrícolas, facilitando no solamente la persistencia de los habitantes originarios, sino también de esas actividades primarias.

Nuestro trabajo de campo se realizó durante el transcurso del año 2012 en el estado de Morelos, México (ver Mapa 1), en los municipios de Jiutepec, Yautepec y Tlayacapan (ver Mapa 2), y más específicamente en los poblados respectivos de Atlacomulco, Oacalco y Tlayacapan. Los poblados de Atlacomulco y Oacalco son los núcleos de población de dos ejidos del mismo nombre, siendo Tlayacapan el núcleo de población de un ejido y de una comunidad agraria, ambos nombrados Tlayacapan. Señalemos que la propiedad de la tierra en México se divide en tres tipos: la propiedad privada, la propiedad ejidal -las tierras repartidas a comunidades campesinas a partir de la Revolución de 1910 - y la propiedad comunal -las tierras usufructuadas desde tiempos remotos de forma comunal por comunidades campesinas, reconocidas o restituidas a partir de la Revolución. 
Mapa 1. Localización del estado de Morelos

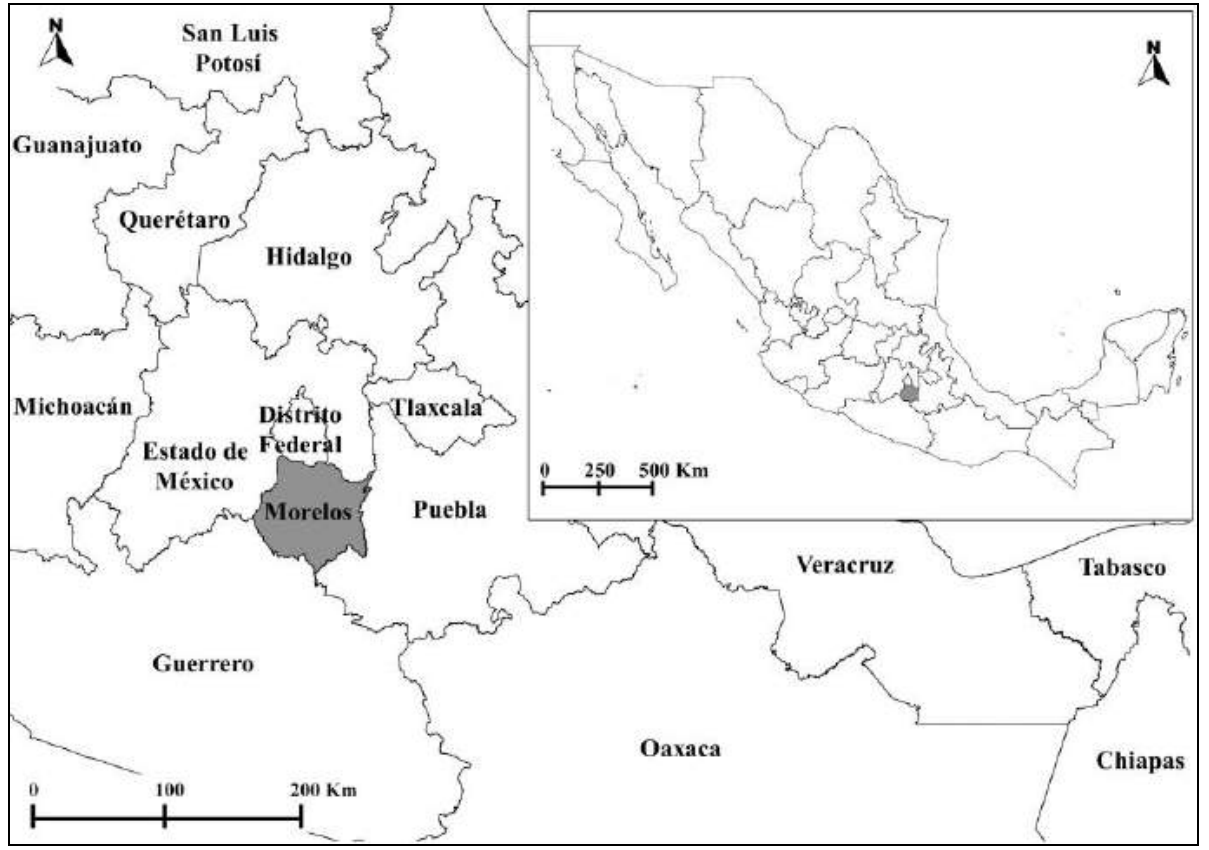

Fuente: Instituto Nacional de Estadística y Geografía (INEGI, 2010a).

Mapa 2. Estado de Morelos: municipios de estudio

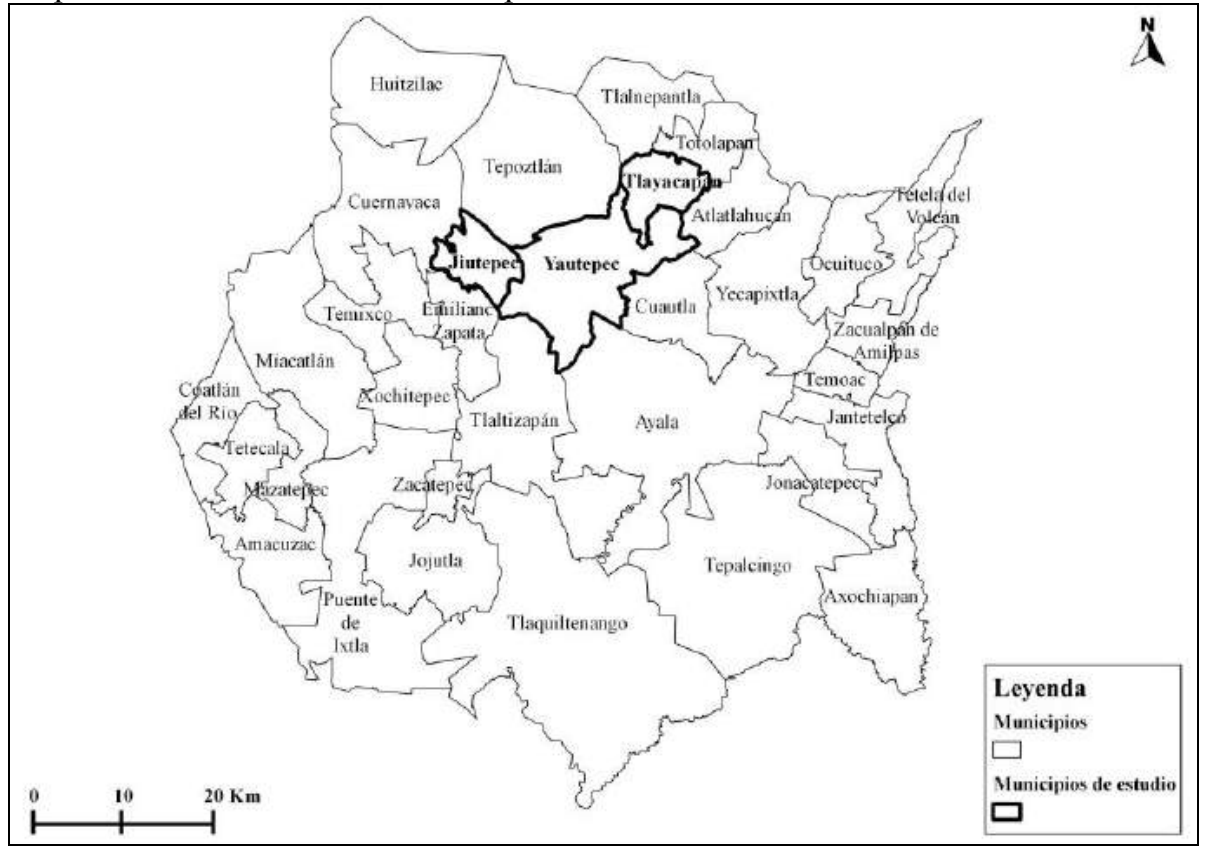

Fuente: Instituto Nacional de Estadística y Geografía (INEGI, 2010a).

La relevancia de los municipios señalados para el estudio de la gentrificación rural se explica por su gran atracción para el establecimiento de casas secundarias destinadas a ocupantes de clases media y alta, provenientes ante todo de la Ciudad de México y generalmente del Distrito Federal. 
Esta atracción es propiciada por el clima cálido de la región, por los diversos atractivos turísticos naturales y culturales, por la cercanía con el Distrito Federal, y por la localización de los municipios en cuestión en un corredor entre Cuernavaca y Cuautla, las dos principales ciudades de Morelos (ver Mapa 3), en donde se concentran los principales servicios en el estado, y, en el caso de Cuernavaca, en donde desde los años 1940 se empezaron a construir las primeras casas secundarias para habitantes acomodados de la Ciudad de México.

Mapa 3. Estado de Morelos: zonas urbanas y ciudades principales (habitantes, 2010)

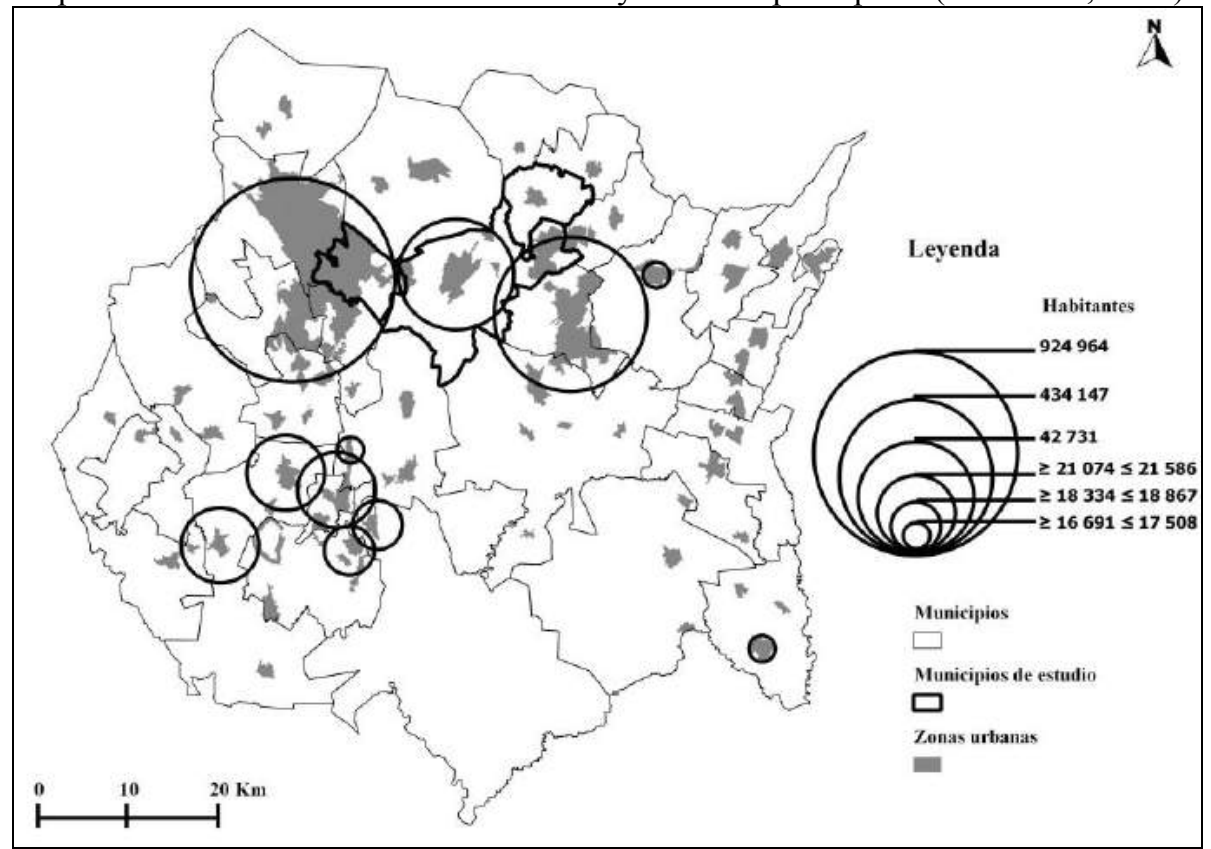

Fuente: Instituto Nacional de Estadística y Geografía (INEGI, 2010a, 2010b).

Se realizaron para el trabajo de campo entrevistas semiestructuradas a productores agrícolas y a habitantes rurales originarios, con el objetivo de alcanzar una saturación de información con relación a los temas a tratar. Así, se efectuaron alrededor de 20 entrevistas en cada una de las tres localidades.

En los ejidos y la comunidad agraria en cuestión se practica una agricultura comercial de pequeña escala, específicamente la producción de plantas ornamentales en el ejido de Atlacomulco, en el municipio de Jiutepec; la producción de caña de azúcar y hortalizas, y el cuidado de ganado vacuno en Oacalco, municipio de Yautepec; y la producción de maíz y hortalizas en Tlayacapan. La agricultura en los tres ejidos (Atlacomulco, Oacalco y Tlayacapan) es de irrigación, esencialmente mediante pequeños canales (apantles) conectados a manantiales, mientras que en la comunidad agraria de Tlayacapan las actividades primarias dependen exclusivamente de la lluvia.

\section{La gentrificación rural como factor de anclaje}

Las entrevistas efectuadas en los tres municipios de Morelos mostraron cómo la llegada de habitantes de clases media y alta de la Ciudad de México -turistas, residentes permanentes y sobre todo residentes temporales que han comprado casas secundarias para ocuparlas los fines de semana y los periodos vacacionales- ha impactado la economía y las estrategias de vida locales.

Un tema recurrente en las entrevistas fue la complementariedad entre las actividades agrícolas y las nuevas actividades económicas ligadas al turismo y a los nuevos residentes temporales o permanentes. Estas nuevas actividades económicas son diversas, e incluyen el trabajo doméstico, el trabajo en la construcción, la jardinería, la instalación y limpieza de piscinas, el establecimiento de co- 
mercios y pequeños restaurantes, el trabajo en agencias inmobiliarias, la fabricación y venta de productos artesanales, entre otros.

Se han creado así varias configuraciones de trabajo en los hogares. Un ejemplo común es que el marido trabaje en la agricultura mientras la mujer labora en el sector ligado al turismo y a los nuevos residentes -fabricando y vendiendo productos artesanales, administrando un pequeño restaurante, siendo trabajadora doméstica, u otros. En otros casos, el marido se ocupa a la vez en la agricultura y en actividades no agrícolas, como la jardinería, la limpieza de piscinas, la venta y fabricación de productos artesanales, entre otros, y la mujer puede o no dedicarse a algún trabajo complementario. No obstante, existen muchas configuraciones diferentes dependiendo de los miembros del hogar. Así, por ejemplo, si los hijos en edad de trabajar siguen viviendo en el hogar de los padres, es común que padre e hijos se ocupen en las actividades agrícolas mientras las hijas y la madre trabajen en actividades no agrícolas.

Existen por supuesto hogares en los poblados estudiados que se dedican sólo a la agricultura o sólo a alguna actividad no agrícola, pero la situación más común se asocia a la realización de varias actividades económicas complementarias, en particular la combinación de actividades agrícolas y no agrícolas. Esta complementariedad de los ingresos de las dos actividades es esencial porque tanto los ingresos agrícolas como los no agrícolas vinculados a actividades turísticas y a la llegada de nuevos residentes temporales y permanentes son inseguros y caprichosos.

Por un lado, los ingresos de la agricultura son inseguros por las fluctuaciones en los precios agrícolas, el intermediarismo en la cadena agroalimentaria, las plagas, o las variaciones del clima. Una mala cosecha o la caída de los precios agrícolas pueden ser devastadoras para un hogar solamente dedicado a la agricultura. Por otro lado, los ingresos ligados a la gentrificación rural también son inestables porque están sujetos a la llegada de los turistas y de los nuevos habitantes generalmente temporales-, razón por la cual las familias suelen preservar las actividades agrícolas de forma paralela a las nuevas actividades no agrícolas.

$\mathrm{Al}$ adoptar una estrategia de diversificación de actividades económicas, las personas entrevistadas declaran poder superar en cierta medida el problema de la inseguridad en los ingresos. Existe así, sin duda, una simbiosis entre las actividades agrícolas y las nuevas actividades no agrícolas ligadas a la gentrificación rural, permitiendo una mejora en el nivel vida de los hogares y actuando como seguro contra alguna adversidad.

Algunos casos y testimonios nos ayudan a plasmar esta complementariedad:

La señora Gabriela Bernardino ${ }^{2}$, de 63 años de edad, vive con su marido en el pueblo de Oacalco. Hace alrededor de siete años, con la llegada de más y más residentes temporales a la zona, decidió abrir, en la parte delantera de su casa, un pequeño restaurante, o "fondita", donde prepara quesadillas, pozole, tacos y toda una serie de manjares para los visitantes, así como para la población local. No obstante, hace un par de años, su marido se enfermó del corazón, impidiéndole seguir trabajando. El marido era anteriormente agricultor y ganadero -cultivaba una hectárea de caña de azúcar y cuidaba, junto con la señora Bernardino, una veintena de vacas. A raíz de esta enfermedad, la pareja se vio en la necesidad de poner en alquiler la hectárea de tierra y vender una parte del ganado. A pesar de esta adversidad, el pequeño restaurante tuvo éxito y la señora Bernardino ha logrado mantener su nivel de vida. Ante todo, la combinación de los ingresos del restaurante, del ganado y del alquiler de la parcela ha permitido a la pareja evitar pedir ayuda monetaria a sus seis hijos -que viven todos en Estados Unidos desde hace 23 años-o intentar ir a vivir con alguno de ellos, así como evitar vender su parcela, la cual quieren dejar en herencia.

El señor Octavio Ruiz, de 59 años de edad, vive con su esposa, su hijo, su nuera y su nieta en el poblado de Tlayacapan. Se dedica a la agricultura y a la producción y venta de objetos de alfarería, siendo dueño de un negocio de artesanías que administra con su esposa y su nuera. El desarrollo de la fabricación y venta de artesanías, sobre todo de productos alfareros, ha sido incitado en gran parte por la atracción turística y residencial de Tlayacapan -esencialmente de residencias secundarias. En cuanto a la agricultura, el señor Ruiz es dueño de dos hectáreas que ocupa para producir

\footnotetext{
${ }^{2}$ Señalemos que no se usaron los verdaderos nombres de las personas para respetar su anonimato.
} 
maíz, tomate verde y tomate rojo. Su hijo es también agricultor y artesano, específicamente artesano herrero y ayuda a su padre a trabajar la tierra. Tal y como señala el señor Ruiz, para los productores de hortalizas de Morelos el gran problema ha sido la comercialización de sus productos porque los precios fluctúan mucho. Así como en un año pueden obtener ganancias, en el siguiente pueden perder todo el dinero invertido en el cultivo e incluso endeudarse. En esas circunstancias, la combinación de los ingresos provenientes de la venta de productos artesanales y agrícolas ha sido fundamental para contrarrestar las crisis recurrentes en la agricultura. Según el propio señor Ruiz, los ingresos complementarios de la venta de artesanías le han permitido evitar recurrir a la venta de tierras, al endeudamiento o a la migración laboral, tal y como sucede con frecuencia en pueblos cercanos, donde prácticamente no existen esas actividades económicas complementarias.

El señor Javier Rodríguez, de 40 años de edad, vive con su esposa y sus cuatro hijos en el ejido de Atlacomulco, donde alquila un pequeño terreno de 500 metros cuadrados para producir y vender plantas ornamentales. Anteriormente era jornalero agrícola en sembradios de arroz, tomate rojo y verde, calabaza y maíz, en el mismo ejido de Atlacomulco, pero hace alrededor de 20 años la urbanización empezó a provocar grandes cambios agrarios y agrícolas. Al encarecerse la tierra y al incrementarse la demanda de plantas para los jardines de las nuevas casas y complejos residenciales, muchos de los propietarios de las parcelas empezaron a alquilarlas de forma subdividida para la producción de plantas ornamentales. Esta producción se realiza sobre pequeñas superficies, generalmente menores a los 2 mil metros cuadrados, y en algunas ocasiones en pequeños invernaderos. Las nuevas casas y complejos residenciales también incrementaron la demanda de mano de obra para la jardinería, la construcción, la limpieza e instalación de piscinas, el trabajo doméstico, entre otros. De hecho, el señor Rodríguez es también jardinero en un complejo residencial cercano. Las dos actividades económicas le han permitido permanecer en su localidad de origen, pues anteriormente había emigrado a Estados Unidos junto con sus hermanos para buscar trabajo. El señor Rodríguez regresó de los Estados Unidos hace seis años, estableciendo en ese momento su vivero, aunque trabajaba desde antes como jardinero. Al tener ya mucho trabajo con sus dos actividades económicas, afirma que no piensa volver a emigrar: "Aquí ya tengo mi trabajo", dice.

En Tlayacapan, un administrador de un conjunto residencial de casas secundarias, que se dedicaba también en su tiempo libre a producir objetos de alfarería comercializados por su esposa, notaba lo siguiente sobre su pueblo:

\begin{abstract}
Acá, si no sabes, aquí son alfareros, se dedican las familias, y a la agricultura. [...] Como es un pueblo que da servicios, que viene gente aquí del D.F. [Distrito Federal], pues ya nos dedicamos un poquito más a eso, al comercio, a la venta de alfarerías. [...] [Antes] no había, estaba muy olvidado este pueblito. Pero como cuando se abrieron ya otras vías de comunicación, a Xochimilco, eso fue lo que nos dio más vida a este pueblo. Le dio más... un nivel más económico. [...] Pero el campo hay veces que no es rentable. Entonces realmente casi sale uno a veces al parejo, o a veces sale uno perdiendo en el campo. Por eso ya nos dedicamos un poquito, también, al comercio. [...] Imagínese la derrama económica de todos los fines de semana. Acá se viene a derramar mucha lana [mucho dinero]. Y la verdad sí, nosotros agradecemos mucho al turismo porque sí deja una derrama económica considerable al municipio. (Administrador de un conjunto residencial y artesano alfarero de 47 años de edad, habitante de Tlayacapan).
\end{abstract}

Este último testimonio resume muy bien la complementariedad entre los ingresos inciertos de las actividades agrícolas y los ingresos de actividades no agrícolas, que surgen con la llegada de turistas y residentes temporales y permanentes provenientes de la Ciudad de México.

A pesar del efecto positivo de la creación de empleos asociado a la gentrificación rural, las opiniones de las personas entrevistadas son en general mixtas: por una parte reconocen esa creación de empleos y la mayor demanda de productos y servicios, pero por la otra se preocupan por la pérdida de los espacios agrícolas y de los paisajes rurales y naturales, así como por la pérdida del sentido de pertenencia. Varios testimonios reflejan esta visión:

"Por una parte, pues hay más trabajo, hay más ventas, todo eso pues, pero por la otra se van perdiendo los espacios." (Productor de plantas ornamentales de 34 años de edad, habitante de Atlacomulco). 
Ha sido un cambio bastante drástico la verdad. Estamos aprovechándonos de los campos, desgraciadamente. Pero también ha sido una manera de generar empleos. [...] Porque por ejemplo toda esta zona estaba sin utilizarse, ya no la sembraban, y ahora [con la construcción] nos ha ayudado a generar empleos, bastantes. Y ahorita en tiempo de obra es mucha la gente que se utiliza... 200-300 gentes y la mayoría son de la zona. (Promotora inmobiliaria de 46 años de edad, habitante de Oacalco).

Bueno, con decirle, los venados, los matábamos ahí dónde es ahora el campo deportivo. Porque todo ese caserío, por allá para Lomas [de Cocoyoc] todo eso, no existía nada, nada, nada. Eran puras huertas de mangos, bosques que eran. [...] Pero ahora sí que hubo mucho trabajo y equis cosas, pero pasaron a fregar porque hubiera visto qué bonito era. Si se iba para el bosque, encontraba racimos de plátanos, café, papaya... maduros. De todo, mangos... (Productor de maíz y artesano de 72 años de edad, habitante de Tlayacapan).

Pues yo creo que sí va a traer beneficios, pero por otro lado, [...] siento que va a perder, o de hecho ya está perdiendo su... digamos su arraigo, de pueblito, como lo era antes. [...] Igual, la mayoría que está construyendo casas aquí, digamos que es gente con dinero, que nada más viene a su casa de descanso y se va. Igual le puede dar empleo a, no sé a las mujeres de aquí del pueblo, a las señoras que vayan a limpiar, asean tres veces, les dan su dinerito, y ya se regresan. Jardineros... Pues eso, yo digo que sí beneficiaría, pero pues sí, no perder su arraigo del pueblo, como era antes. (Comerciante de objetos de alfarería de 25 años de edad, habitante de Tlayacapan).

\section{Efectos negativos de la gentrificación rural}

En cuanto a los efectos negativos de la gentrificación rural, es importante señalar que en pocas entrevistas se mencionó algún efecto de desplazamiento. Sin embargo, es necesario aquí hacer la distinción entre los agricultores propietarios de sus parcelas y los agricultores que alquilan las parcelas que cultivan.

Los agricultores propietarios no son afectados directamente por el desplazamiento, aunque muestran una preocupación por el incremento en los precios de los terrenos porque esto les dificulta alquilar o comprar tierras adicionales para aumentar su producción. Los agricultores arrendatarios, que son una minoría salvo en el caso del ejido de Atlacomulco, sí se han preocupado por el posible efecto de desplazamiento, resultado del incremento en el costo del alquiler de la tierra y de la conversión del uso de suelo para la construcción de casas y complejos residenciales. No obstante, muchos moderan esa preocupación sabiendo que podrán alquilar tierras a un menor precio en localizaciones menos accesibles o en ejidos y municipios aledaños donde la gentrificación rural todavía no es un problema. Estos casos no consisten en un desplazamiento del lugar de residencia, como se describe en la literatura de la gentrificación, sino en un desplazamiento del lugar de trabajo agrícola. Los siguientes casos y testimonios son significativos:

El señor Ricardo López, de 73 años de edad, es un productor de plantas ornamentales en Atlacomulco. Trabaja junto con dos hijos suyos, a quienes planea heredar el negocio familiar en dos o tres años. Si bien el señor López ha trabajado en la producción de plantas ornamentales desde hace alrededor de 20 años, inauguró su vivero actual hace apenas un año sobre un terreno alquilado de mil metros cuadrados. Anteriormente producía plantas ornamentales en otro terreno alquilado, situado más cerca del camino principal a la ciudad de Jiutepec, pero el propietario de ese terreno decidió venderlo a una empresa de construcción de conjuntos residenciales. Así, el señor López se vio obligado a buscar otro terreno para alquilar, encontrando un terreno más lejano, aunque más económico, en el mismo ejido. Sin embargo, la preocupación de ser obligado a cambiar una vez más de terreno persiste: "Aquí ya están vendiendo. Ya están construyendo aquí también. Aquí no tarda a que nos echen para afuera... Y cada año están subiendo 100 pesos [el alquiler]."

La señora Sofía Alcántara, de 58 años de edad, trabaja desde hace aproximadamente 20 años como productora de plantas ornamentales en Atlacomulco. Anteriormente ayudaba a su marido a producir, pero él falleció hace nueve años. Ahora trabaja junto con su hija y un empleado. Uno de los grandes problemas que relata la señora Alcántara, al alquilar la tierra donde produce, es cómo ha sido obligada varias veces a cambiar de terreno al decidir los propietarios subdividir las parcelas y 
alquilarlas a varias personas, o venderlas a la industria de la construcción. La señora Alcántara se ha visto asi en la necesidad de cambiar dos veces su parcela. Su primer vivero lo administraba junto con su marido. Después de haber alquilado el terreno durante siete años, el propietario les pidió su devolución. La señora Alcántara y su marido perdieron gran parte de la infraestructura que habían construido. En sus propias palabras: "Todo lo que había metido de inversión se me vino abajo. Mi esposo todavía en vida hizo una cisterna para recabar el agua para fertilizar. [...] Y hasta una bodega." En cuanto a su segundo terreno, el propietario le pidió devolverlo en tan sólo dos años. Actualmente su vivero está en un terreno alquilado de mil metros cuadrados, pero se trata de un vivero cubierto, uno de los pocos de Atlacomulco, permitiéndole producir plantas más caras como la flor de Nochebuena. Sin embargo, al haber invertido mucho dinero en instalar el invernadero, la señora Alcántara tiene una gran preocupación de ser obligada una vez más a cambiar de parcela.

Otra productora de plantas ornamentales de Atlacomulco, que junto con su marido eran de los pocos productores propietarios de su terreno en ese ejido, mencionó lo siguiente respecto a la construcción de casas y conjuntos residenciales:

Pues a mí en lo personal pues no [me afecta], porque trabajamos en lo propio, pero por ejemplo los que rentan pues sí. Como las gentes que estaban rentando ahorita allá, ellos sí. Ellos estaban ahí y el dueño vendió y les pidió que desocuparan. Entonces ellos, los que están rentando, son los que sí se ven en un aprieto. [...] Pero a nosotros en sí, a mí, no me afecta en nada, pero los que rentan sí porque les quitan. Les piden el cacho que estaban rentando para hacer casas. (Productora de plantas ornamentales de 37 años de edad, habitante de Atlacomulco).

En ningún momento, subrayémoslo, se habló de un desplazamiento del lugar de residencia, sino de desplazamientos del lugar de trabajo agrícola. Es interesante señalar que todas las familias entrevistadas (más de 60), salvo dos, eran propietarias de su vivienda. En lugar de un desplazamiento residencial tiende a existir, en los municipios de estudio, una segregación socio-espacial entre los lugares de residencia de los habitantes originarios -generalmente los pueblos-y los lugares de residencia de los nuevos habitantes temporales y permanentes de clases media y alta provenientes de la Ciudad de México - estableciéndose normalmente en casas y complejos residenciales de lujo a las orillas o a las afueras de los poblados, donde hay más espacio para jardines, piscinas y otras amenidades. En otras palabras, la gentrificación rural en los municipios de estudio afecta ante todo a los terrenos agrícolas, no a los espacios residenciales en los pueblos.

Con la excepción de los productores arrendatarios -siendo una minoría salvo en el caso del ejido de Atlacomulco-, las preocupaciones principales de los habitantes originarios con relación a la gentrificación rural no están ligadas al desplazamiento. En los tres poblados, pero especialmente en Tlayacapan, las personas entrevistadas mostraron una gran preocupación acerca de las diversas irregularidades en el mercado de tierras, tales como el incumplimiento de lo estipulado en los contratos de compra-venta y otros abusos por parte de los compradores, la venta ilegal de tierras ejidales y comunales, la corrupción de las autoridades ejidales y comunales para permitir e incitar la venta de tierras, entre otros.

Notemos que la venta de las parcelas ejidales en México está fuertemente regulada. Salvo la figura de la cesión de derechos, es decir la venta o la herencia de las parcelas a avecindados o a otros ejidatarios, la venta de las parcelas a personas exteriores al ejido implica su conversión a dominio pleno, equivalente a la propiedad privada, debiendo ser autorizada por una mayoría en la asamblea de los ejidatarios. En el caso de las comunidades agrarias, la ley no permite la venta de las parcelas para desincorporarlas de la comunidad, sólo permite la cesión de los derechos parcelarios a familiares o vecinos. No obstante, varias formas de venta irregular e ilegal de tierras existen, especialmente por medio de la corrupción de las autoridades ejidales o comunales, utilizando la figura de la cesión de derechos para realizar una venta disfrazada a personas exteriores, o empleando documentos apócrifos. Varios testimonios dan fe del disgusto de los habitantes locales con relación a las irregularidades y a los abusos existentes en el mercado de tierras: 
Es un pinche negociazo para los cabrones que compran. [...] Vienen a comprar y les van pagando [a los que venden tierras] migajas. Dicen: "te voy a comprar pero al precio que yo quiera y en las condiciones que yo quiera, si quieres porque sino, no". Les dan [a los que venden tierras] el 5\% del costo del terreno. Y luego hasta que se les hinche su chingada gana. De 5 a $10 \%$ de entrada y luego ya después lo dan hasta el año, o medio año, luego en pagos... ¿Tú crees que así está bien? (Productor de maíz y hortalizas, y artesano y comerciante de objetos de alfarería de 55 años de edad, habitante de Tlayacapan).

El trienio pasado el comisario ejidal, un compadre mío, [...] ¿sabe las pendejadas que hizo? Aquí se inicia la lucha por la tierra, en Morelos. Y este cabrón como comisario autoriza la venta de... tenemos poco ejido además nosotros... de 300 tareas [30 hectáreas] de ejido que vendió. ¿Para qué? Para construcción. [...] Van a poner un fraccionamiento [un conjunto residencial]. Pero dime una cosa nada más... venden a 150 pesos el metro [cuadrado]. Ve a saber cómo está el precio ahora... mínimo a mil pesos. [...] Y ellos [los comisarios ejidales] con la misión de ganarse un dinero. Échele la llamada: "sabe qué comisario, estoy en tratos con un ejido en Tlayacapan, entonces a lo mejor me puede ayudar. ¿Cuánto me cobra usted por firmármela [firmar la cesión de derechos]?” A ver qué te dice, qué te cuenta... Yo así le hice a un cabrón, le hablé por teléfono: "buenas tardes, ¿comisario ejidal?", "¿sí?", "sabe qué señor, mire estoy en tratos con un ejido en Tlayacapan, quiero que me autorice. ¿Cuánto me cobra?", "pues es que depende de la cantidad”. Le digo: “¿ah, sí? ¡Qué poca madre tienes compadre!" [...]. La gente no piensa. No piensa a futuro. (Productor de hortalizas y antiguo trabajador en la construcción de 63 años de edad, habitante de Tlayacapan).

El comisario de bienes comunales de Tlayacapan, por su parte, reconoció lo siguiente: "La ley agraria lo menciona muy claro, que se puede ceder a la familia o a avecindados. Sinceramente, pues esto nunca se ha cumplido, hasta la fecha nunca se ha cumplido con la realidad. Porque no es cierto que se ceda nada más, se vende a otra gente. Sí, eso no podemos esconderlo porque esa es la realidad." (Productor de maíz y hortalizas, y comisario de bienes comunales de 68 años de edad, habitante de Tlayacapan). Esta persona también resaltó cómo una empresa de construcción de conjuntos residenciales había comprado ilegalmente tierras de la comunidad agraria de Tlayacapan, y cómo a su vez esas tierras fueron invadidas por familias, que construyeron ahí asentamientos irregulares. El caso se llevó al Tribunal Agrario con el fin de restituir las tierras a la comunidad, pero el problema no se había solucionado al momento de la entrevista.

Por otra parte, en las tres localidades, pero especialmente en Oacalco, se expresó una preocupación con relación a la contaminación y el uso excesivo del agua causada por los nuevos desarrollos inmobiliarios (especialmente para regar jardines y llenar piscinas) y, añadamos, por la incapacidad de los gobiernos municipales de mejorar la infraestructura hidráulica y el manejo de desechos. Varios testimonios reflejan esa preocupación:

"Es que nos contaminan el agua, [...] sale muy contaminada. Porque en aquellos campos no nos dejan sembrar hortalizas. Por las aguas negras que tiene el agua." (Productor de caña de 54 años de edad, habitante de Oacalco).

"Pues sí, sí nos afecta [la construcción de casas], porque el agua se escasea. Ya no la dejan como antes. Hágase cuenta que ahora la entuban y la mandan... ya no llega igual que antes. Antes, o sea el canal casi al ras, ahorita llega a menos de la mitad." (Productora de plantas ornamentales de 39 años de edad, habitante de Atlacomulco).

Ahí donde está la caseta [de peaje] sembraban caña. En [el barrio de] 11 de Mayo también sembraban caña. De la barranca para acá. Ahora son casas. Todo eso eran campos de producción [...]. Ahora ya no siembran mucha caña en los campos estos porque a veces ya no alcanza el agua para las siembras. Ahora son siembras ligeras, tomate, jitomate, milpas. Bueno tomate y jitomate ya no se ha sembrado, ya no quieren jalar [crecer]. Quien sabe por qué. [...] El agua ya está muy contaminada. Antes hasta sembraban cebolla. Pero como la cebolla está enterrada... Se sembraba lechuga también. Pero la contaminación del agua, pues no, saben las personas que no, que está canijo [difícil]. [...] Se arregla que van a meter agua limpia para allá, pero tienen que tapar todo eso para que no echen... un montón de cosas: vasos de plástico, basura, botellas... (Productor de caña jubilado de 86 años de edad, habitante de Oacalco). 
A final de cuentas todo esto se va a seguir poblando. Sí, porque ahí por donde están haciendo casas antes eran campos, todos esos eran sembradíos de pura caña. Y ahora pues los vendieron y ya están haciendo fraccionamientos [conjuntos residenciales] y todo eso. [...] Pues se va a perder todo lo que en mi infancia... por ejemplo, este lugar no existía, era todo un terreno... Y ahí pasaba un canalito, de hecho el puente era una canaleta donde pasaba agua cristalina, que servía para todo. Y ahora desgraciadamente todo eso se perdió. [...] Desgraciadamente ahora ya no es así, ahora puras aguas negras. Por eso le digo, en ese aspecto pues sí nos afecta, creo que a todos, no sólo a mí. Entonces eso es lo que a mí no me gusta de lo que está pasando. Sí, porque yo de niño hasta me bañaba en el río, ahora ni de chiste. Ya todos los drenajes están cayendo allí.” (Empleado de restaurante de 27 años de edad, habitante de Oacalco)

\section{Conclusiones}

Esta investigación sobre los efectos de la gentrificación rural en Morelos demuestra el error de tratar de generalizar el efecto de desplazamiento. Queda claro que el desplazamiento residencial está asociado a una situación específica en donde la gentrificación afecta a inmuebles antiguos previamente ocupados (a diferencia de la construcción de nuevos inmuebles en espacios no habitados), y en donde los habitantes originarios son arrendatarios -explicando por qué deben cambiar de residencia cuando se incrementan bruscamente los alquileres o cuando los propietarios no renuevan los contratos de arrendamiento. En el contexto rural, los habitantes originarios suelen ser propietarios de sus casas y tierras, y, en el caso de Morelos, la gentrificación se produce con la construcción de casas nuevas en parcelas agrícolas (con el fin de aprovechar los amplios espacios), no con la renovación de casas antiguas en los pueblos. Por lo tanto, el desplazamiento residencial es, según nuestra investigación, irrelevante en los municipios de estudio.

No obstante, nuestro trabajo de campo dejó en claro que sí existen casos de desplazamiento, aunque no residencial sino del lugar de trabajo de algunos productores agrícolas arrendatarios (casi exclusivamente en el ejido de Atlacomulco). Sin embargo, como ya lo indicamos, estos desplazamientos suelen ser de corta distancia, teniendo lugar dentro del mismo ejido, o implicando a lo mucho la búsqueda de tierras en ejidos o municipios vecinos. En definitiva, la generalización del efecto de desplazamiento (residencial u otro) no se justifica con base en nuestro estudio.

Por otra parte, sí se observó una pérdida del sentido de pertenencia en muchos casos, sin embargo nos resistimos a designar este fenómeno como un desplazamiento sociocultural o como un desplazamiento indirecto, en el primer caso porque se trata más bien de un uso figurado del concepto de desplazamiento (¿por qué no usar las nociones de cambio o vuelco sociocultural?), y en el segundo caso porque en ninguna entrevista se indicó que la pérdida del sentido de pertenencia pudiera llevar al cambio residencial de las personas afectadas. Al contrario, las personas entrevistadas consideran que la gentrificación proporciona los medios y los motivos para permanecer en sus localidades de origen gracias a la creación de nuevos empleos en la construcción, los servicios y el comercio.

En suma, nuestra investigación de campo demuestra que la gentrificación puede ser, en ciertos contextos, un factor de anclaje para la población originaria al incitar la creación de empresas y empleos locales que permiten evitar las migraciones residenciales o de trabajo, ya sean a las ciudades de Morelos, a los estados vecinos, o a los Estados Unidos. Además, la complementariedad entre los ingresos del campo y de actividades no agrícolas ha sido particularmente útil para asegurarse contra la inestabilidad de ingresos así como para reducir el impacto de las adversidades en cualquiera de los dos sectores - por ejemplo, al caer los precios agrícolas o al perderse el empleo no agrícola. Por medio de esa complementariedad, la gentrificación rural puede, en algunos casos, impulsar la persistencia de las actividades agrícolas.

Sin embargo, no podemos argumentar que la gentrificación rural ha implicado un impacto meramente positivo en los poblados de estudio. Algunas de las preocupaciones principales con relación a la gentrificación rural se han vinculado a las irregularidades y abusos en el mercado de tierras especialmente en Tlayacapan -, y a la contaminación y el uso excesivo del agua por parte de los nuevos desarrollos inmobiliarios -sobre todo en Oacalco. 
Ante la multiplicidad de impactos positivos y negativos de la gentrificación rural y urbana, muchos de los cuales apenas se están empezando a investigar, no consideramos acertado incluir en su definición alguno o varios de estos efectos, ya sea el desplazamiento o cualquier otro. Los impactos de la gentrificación son diversos -y a veces contradictorios-, y son contingentes a situaciones específicas, por ende no pueden constituir elementos definitorios. No obstante, tal como lo indican Laurie Guimond y Myriam Simard (2010: 460), un estudio integral de la gentrificación debe incluir el análisis de sus efectos, tanto los negativos como los positivos. 


\section{REFERENCIAS}

Byrne, P.J. (2003). “Two Cheers for Gentrification”. Howard Law Journal 46(3), 405-432.

Davidson, M. y Lees, L. (2010). "New-Build Gentrification: its Histories, Trajectories, and Critical Geographies". Population, Space and Place 16, 395-411.

Freeman, L. (2005). "Displacement or Succession? Residential Mobility in Gentrifying Neighborhoods". Urban Affairs Review 40(4), 463-491.

- (2008). "Testimony of Lance Freeman to The National Commission on Fair Housing and Equal Opportunity", http://www.prrac.org/projects/fair_housing_commission/atlanta/freeman.pdf (consultado el 24 de marzo de 2014).

Glass, R. (1964). "Introduction: aspects of change". En: Centre for Urban Studies, London: Aspects of Change (pp. xiii-xlii), Londres: MacKibbon and Kee.

Guimond, L. y Simard, M. (2008). "Néo-ruralité et embourgeoisement des campagnes québécoises: un regard nuancé". Trabajo presentado en el XLVe Colloque de l'Association de Science Régionale de Langue Française (ASRDLF), Rimouski, Canadá, agosto de 2008.

- (2010). "Gentrification and Neo-Rural Populations in the Québec Countryside: Representations of Various Actors". Journal of Rural Studies 26, 449-464.

Instituto Nacional de Estadística y Geografía. (2010a). Marco Geoestadístico 2010 [Archivo de datos], http://www.inegi.org.mx/geo/contenidos/geoestadistica/m_geoestadistico.aspx (consultado el 24 de marzo de 2014).

- (2010b). Censo de Población y Vivienda 2010 [Archivo de datos]. http://www.inegi.org.mx/est/contenidos/proyectos/ccpv/cpv2010/Default.aspx (consultado el 24 de marzo de 2014).

Lees, L., Slater T. y Wyly, E. (2010). “Introduction”. En: Lees, L., Slater, T. y Wyly, E. (Eds.). The Gentrification Reader (pp. xi-xxiii), Londres y Nueva York: Routledge.

Simard, M. (2007). "Nouvelles populations rurales et conflits au Québec: regards croisés avec la France et le Royaume-Uni”. Géographie, Économie, Société 9(2), 187-213.

- (2011). "Transformation des campagnes et nouvelles populations rurales au Québec et en France: une introduction". Canadian Journal of Regional Science / Revue canadienne des sciences régionales 34(4), 105-114.

Slater, T. (2009). "Missing Marcuse. On gentrification and displacement". City 13(2), 292-311.

Vigdor, J. (2001). "Does Gentrification Harm the Poor?" Trabajo presentado en el BrookingsWharton Conference on Urban Affairs, Washington D.C., octubre de 2001.

- (2002). "Does Gentrification Harm the Poor? Brookings-Wharton Papers on Urban Affairs, 133-173.

\section{SOBRE EL AUTOR}

Matthew James Lorenzen Martiny: Doctorando en sociología en la Universidad de Paris 1 Panthéon-Sorbonne, Francia, y maestro en estudios regionales en el Instituto de Investigaciones Dr. José María Luis Mora, México. Se ha especializado en temas de sociología y geografía rural, particularmente en los efectos de la urbanización en la agricultura y en las comunidades rurales y rurbanas de la región centro de México. 